\title{
The Persistent-Effect Mechanism on the Development of Returning Home to Start a Business in China from the Perspective of Structuration Theory
}

\author{
Tianxue Li \\ Beijing Normal University, Beijing, China \\ Email:118810918990@163.com
}

How to cite this paper: Li, T.X. (2019) The Persistent-Effect Mechanism on the Development of Returning Home to Start a Business in China from the Perspective of Structuration Theory. Open Journal of Business and Management, 7, 1485-1493. https://doi.org/10.4236/ojbm.2019.73102

Received: July 5, 2019

Accepted: July 26, 2019

Published: July 29, 2019

Copyright () 2019 by author(s) and Scientific Research Publishing Inc. This work is licensed under the Creative Commons Attribution International License (CC BY 4.0). http://creativecommons.org/licenses/by/4.0/

\begin{abstract}
As Chinese economy enters a new normal, returning home to start a business has become an important element of economic development. By literature study and field survey, it indicates that the behavior of migrant workers returning home to start a business in China is a dynamic process with the interaction between migrant workers and social structure. Therefore, this paper starts to restructure the persistent-effect mechanism of the development of returning home entrepreneurship with resources and rules based on the structural theory perspective. The government should strengthen cooperation between government and business to cultivate applied talent jointly, and accelerate the upgrading of industrial structure. As for the enterprises, they ought to make long-term planning, study to leverage existing policies and build strengths and avoid weaknesses. Meanwhile, they should take the initiative to create distinctive corporate culture.
\end{abstract}

\section{Keywords}

Returning Home to Start a Business, Structuration Theory,

Persistent-Effect Mechanism

\section{Introduction}

Migrant workers' returning to their hometowns to build businesses plays an important role in mass entrepreneurship and innovation and also becomes the booster of Rural Vitalization Strategy [1]. The economy it formed has served as a new engine for stabilizing and promoting China's economic and social development. At the same time, exploring whether the returning economy develop- 
ment degree keeps pace with economic development status, seeking methods to prevent farmers from becoming poor again due to the failure of entrepreneurship failure, expanding the positive driving effect of the returning economy and achieving long-term development, are becoming the new focuses of academic research. This paper, taking the industrial cluster area of Z County, Henan Province for example, using non-participant observation reviews the domestic and foreign scholars' structural research on migrant workers' returning to their hometowns to build businesses, and takes an interview and non-participatory observations to local government, entrepreneurs of returning migrant workers and local villagers. And, the paper also uses structural theory to summarize their current development mechanisms, further identify potential problems, and explore the persistent-effect mechanism of returning to the economy. This paper innovatively explores issues from three aspects of social background, resources and rules, simplifies the problems of migrant workers returning to their hometowns and proposes targeted suggestions, which will help more scholars to conduct in-depth research. Despite this, there is still a lot of room for expansion. The perspective of the structured interpretation of the current mechanism is not comprehensive enough, and the social environment is partially overlapped with resources and rules. If the paper added some measurement tools to the application of structural theory, it will make the analysis results more intuitive and more convincing.

The outline of this paper is arranged as follows: the part of introduction mainly concerns study background, content and arrangement. In order to build a theoretical framework, the second Section cites the existing research literature on structural theory and the return of migrant workers to entrepreneurship. The third Section briefly describes the research methods adopted in this paper. The fourth Section overviews the actual situation and research value of the county $\mathrm{Z}$. The fifth and sixth Sections are the core of the empirical part. The author uses the structural theory to explain the development mechanism of the current $\mathrm{Z}$ County migrant workers returning to their hometowns, and then aim at the existing problems to re-structure a persistent-effect mechanism.

\section{Mechanism Construction Theory Citation}

In this paper, at home and abroad by combing literature, the author finds that domestic and foreign academic circles have little research on the persistent-effect mechanism of returning to the economy from the perspective of structuration theory, which also leads to the current research bottlenecks. The purpose of this study is to analyze typical cases through a structured perspective, so as to promote the universal mechanism applicable to the long-term development of China's returning economy, and promote the rural revitalization strategy. Therefore, relevant research on structural theory, migrant workers returning to their hometowns, and returning to the home economy has provided strong theoretical support for this study. 


\subsection{Structural Theory Research}

Modern sociology that emphasizes social objectivity and postmodernism that emphasizes human action have argued on the relationship between subjectivity and subjectivity. In this context, British sociologist Giddens proposed structural theory based on the theory of predecessors. He believes that the objectivity of society and the subjectivity of human beings are not independent or antagonistic, but rather a dynamic of mutual influence and mutual construction. According to structural theory, on the one hand, the structure of society limits people's actions and influences their values; on the other hand, changes in people's actions and concepts can counteract social structures. This results in the collapse of the original binary opposition between subjective and objective and promotes the development of sociology. Structural theory interprets structures as a collection of rules and resources. The rules include three dimensions: ideographic rules, dominant rules and legalization rules. The ideographic rule is a symbolic order, which is embodied as an explanatory diagram. Dominant rules are the means by which actors can rely directly on the implementation of power. The legalization rules are constraints on human actions and are directly manifested in various legal systems. Resources are divided into configuration resources and authoritative resources. Dispositional resources refer to objective material resources that people have, while authoritative resources refer to non-physical resources that people use in their practice. The rules and resource connotations are jointly embodied in practical actions. They have an impact on people's subjective initiative in practice, and at the same time they are constructed by human actions. However, some scholars believe that Giddens's theory of structuring does not really get out of the dilemma of subjective and objective binary opposition, because it overemphasizes the role of human practice consciousness in the whole process of interactive construction, paying attention to perceptual consciousness, which is the expression of favoring human subjective initiative and belittling social objectivity.

In sum, the structural theory provides a more scientific theoretical framework for us to analyze the dynamic social construction process of migrant workers returning to their hometowns.

\subsection{Research on Migrant Workers Returning to Their Hometowns}

In China's urban-rural dual system and macroeconomic background, the phenomenon of migrant workers returning to their hometowns has culminated with the outbreak of the 2008 financial crisis. The Fifth Plenary Session of the 16th CPC Central Committee proposed the construction of a new countryside. Some scholars began to pay attention to the phenomenon of migrant workers returning, which focused on the causes and significance of the return. Later research mainly focuses on the reasons and motivation mechanism of migrant workers returning to their hometowns under the background of financial crisis, and the dilemma and policy recommendations for entrepreneurship. In 2010, the No. 1 
Document of the Central Committee put forward the concept of "new generation of migrant workers", which led to a heated discussion in the academic circles. Research represented by Zhang F. [2], Zhang G.Q. [3], Wang G.M. [4] and others focus the citizenization, employment quality and the willingness to return home of the new generation of migrant workers. From 2017 to the present, the proposal of rural revitalization strategy has provided new horizons and new perspectives for scholars to study the return of migrant workers to their hometowns. The research has gradually shifted from policy advice to new models and new paths and the significance of the rural revitalization strategy.

From the previous studies, it can be seen that migrant workers returning to their hometown mainly have included four characteristics: from the perspective of industrial structure, the types of farmers returning to their hometown are mainly concentrated in the first and second industry, and high-tech industries and high level service industries account for a small proportion; from the perspective of enterprise scale, enterprises are generally small in scale, and their modes are mainly individual business; from the perspective of enterprise types, more survival-oriented enterprises primarily and less opportunity-based entrepreneurship; from the perspective of the life cycle of enterprises, the cycle is generally short and the capacity for sustainable development needs to be strengthened. Therefore, it indicates that how to explore and continuously expand the role of returning home business to the rural revitalization strategy, coordinated development of county economy is the focus of future research.

\section{Research Methods}

This paper is based on the investigation of the Z-county industrial cluster area, complemented by extensive literature review by domestic and foreign scholars, summarizing and refining the current mechanism of returning home to start business in the central part of China. In particular, this paper uses the semi-structure interviews, non-participatory observations and historical document to try to propose a universal mechanism applicable to the persistent-effect development of the returning home to start business in the future.

\section{Overview of Z County Industrial Cluster Area}

The completion of the $\mathrm{Z}$ County Industrial Cluster is a major initiative of the local government in response to the call of the central government. Local government departments have integrated idle land to establish parks, accelerating the attraction of industrial and urban resources to gather here, providing fertile ground for returning entrepreneurial migrant workers, and driving the employment of local surplus labor. Z County Industrial Cluster is located in the south of Henan Province, between Zhengzhou and Wuhan. It has a planned area of 11.6 square kilometers, with prominent geographical advantages and developed transportation network. As of April 2018, there were more than 120 enterprises in the agglomeration area, with a total investment of 12.5 billion yuan and more 
than 15,000 employees. In terms of supporting infrastructure, Z County Industrial Cluster District focuses on improving carrying capacity, building road networks, building low-rent housing and public rental housing, effectively protecting the lives of enterprises and employed employees, and promoting complementary functions and resource sharing between industrial clusters and main urban areas; In terms of scientific and technological innovation, the county government has set up a corporate innovation fund to support enterprises to carry out independent innovation, develop 4 high-tech enterprises, set up 3 engineering technology research and development centers, and establish 2 production and research bases of Shandong University and Henan University of Science and Technology.

Therefore, the $\mathrm{Z}$ County Industrial Cluster is a typical returning entrepreneurship demonstration zone. Its development situation, industrial structure level and potential development problems/development hazards are enough to provide reference and reference for the development of rural migrant workers in China.

\section{The Current Development Mechanism of Z County's Returning Economy: A Structured Interpretation}

\subsection{The Structural Background of Returning Home to Start Business: Social Environment}

As the American sociologist Peter Blau said in the On Limitations of Rational Choice Theory for Sociology, the central task of sociology is not to explain individual behavior, but to explain how the social environment structure affects people's life changes. As a new form of rural economy, the development of the returning economy is a behavior produced in a specific social environment.

Henan Province, a large province of labor export and a large agricultural province, actively responded to the central government to create a favorable environment for migrant workers to return to their hometowns. The $\mathrm{Z}$ county policy support researched by the author has been put in place and the entrepreneurial atmosphere is strong. Farmers generally believe that they can pursue a happy life in their hometown as same as in city. The returning enterprises have obvious effects on the local surplus labor. In the micro-environment, the first generation of migrant workers in Z County entered the middle-aged occupation crisis, and the severe employment situation in the city was unfavorable to them. The returning home business changed the status of migrant workers, from migrant workers to bosses, and farmers who returned to work. Workers have also become formal skilled workers with stable jobs, bringing them social status improvement and self-perception changes. At the same time, the practice of piano production by the migrant workers has improved the human capital of migrant workers themselves. The rural area retains the original social relationship network for entrepreneurship. The surplus labor resources are abundant, the trust is high, and the social structure resources are abundant, which shows the potential of economic development. 
However, in the actual situation, there is a fault in the local government's macro-planning and economic development level, lack of sufficient consideration for the feasibility of the project at this stage, and lack of living soil. For example, the Z County Government plans to build a violin culture and art park around the violin industrial park to realize the development of elegant art following the production and sales end. However, the local consumption level is limited, the artistic and cultural atmosphere is not strong, the violin playing talent is scarce, and the violin art culture park is developing. The development of violin art cultural park faces many difficulties. The nepotism generated by the rural social relations network also lays a hidden danger for the long-term development of the returning economy.

\subsection{The Structural Factor of Returning Home to Start Business: Resources}

Resources are an important factor in the economic development of returning homes from a structural perspective. The configuration resources and authoritative resources possessed by migrant workers in the process of returning to their hometowns determine the success of returning home business. Through interviews and investigations, the author found that sufficient allocation resources are an important reason for the current development trend of Z County's returning economy, mainly reflected in technical support, financial support, land subsidies, labor resources, and public infrastructure. The local government took the lead in providing land-based entrepreneurs with convenient land use, reducing the burden of entrepreneurship, and helping returning entrepreneurs to start their profits quickly. Not only that, the construction of industrial agglomeration areas allows the returning enterprises to share the fruits of the accumulation. The enterprises not only have sufficient labor resources and public infrastructure facilities, but also can learn from each other and seek common development. The authoritative resources in the returning home business behavior mainly manifested the emotional support and concept identification of the relatives in the hometown [5]. Because most of the migrant workers who are returning hometown are the first generation of migrant workers, the age is generally over 40 years old, the cultural level is limited, and the opportunity cost of entrepreneurship is lower. Coupled with the government policy propaganda in place, the attitude of family members in the hometown is generally agreed to support this kind of behavior that can balance the family business and make a big difference.

In terms of resource acquisition, most of the allocation resources come from government support, and the autonomy of entrepreneurial farmers' representatives needs to be improved. Moreover, the quality of the labor force is low, the training system for technical personnel is imperfect, mostly the mentoring system, the dependence is strong, and the industrial development is constrained. Not only that, the new generation of migrant workers returning fewer entrepreneurs, the second generation of the farmer and their relatives and friends also 
have objections to the returning behavior, which makes the economic development of returning home lack endogenous power, the economic quality of returning home is poor, the enterprise. The first and second industries are mostly.

\subsection{The Structural Factor of Returning Home to Start Business: Rules}

The rules not only support and standardize the development of the returning economy, but also play a role of restraint and restriction in the dynamic development process. In the practice of farmers returning to their hometowns, the value of the rules is mainly reflected in the support of the normative system for farmers to return to their hometowns. The most direct performance is the government's various policy support. Under the background of rural revitalization strategy, the government introduced preferential policies to create a good structural environment and rules for returning home business, helping enterprises to achieve long-term development, thereby driving the development of the local economy and improving people's living standards. The entrepreneurial farmer representatives can make full use of the advantages of the rules, obtain more resources, and achieve the consolidation and development of the enterprise. At the same time, the growth of the company can further promote the transformation of the local environment in a direction that is beneficial to itself. At the same time, corresponding to resources, rural social concepts, customs and other rules affect the acquisition of authoritative resources.

Using the documents published by the government as the material, the author summarizes the policy rules in the process of returning migrant workers to their hometowns into four aspects: fiscal and taxation, financial aspects, land use and supporting measures. Among them, the policy rules that support the positive support mainly include: special support funds, interest-free loans, land subsidies, entrepreneurship training and related public infrastructure, and the restrictive rules mainly include the support fund is not in place, the loan application threshold is high, and the land is used. The subsidy period is short, and the training is separated from the actual factors.

\section{Re-Structuring of the Returning Economy: Research on Long-Term Development Mechanism}

As mentioned above, problems such as policy faults, nepotism, endogenous motivation, short-term migrant workers themselves have caused the returning economy to encounter bottlenecks in its long-term development. To this end, this study believes that the re-structuring of the returning economy should be promoted mainly from the aspects of resources and rules to ensure its long-term development.

\subsection{Resources: Focus on the Cultivation of Applied Talents and Accelerate the Upgrading of Industrial Structure}

The shortage of talents and the restriction of industrial structure are the two 
major obstacles for returning entrepreneurs. In the process of re-structuring, we should pay attention to the cultivation of applied talents and accelerate the upgrading of industrial structure.

The main aspects of talent cultivation are the introduction of foreign talents, the introduction of foreign technical talents, improvement of the local new professional farmers training system, and the mobilization and cultivation of the "second generation". Technology is the primary productive force, and high-end technical talents are the source of motivation for returning home-based entrepreneurs. Through enterprise research, industry-university-research integration, and talent incentive policies, we will focus on the introduction and training of entrepreneurial innovation core talents that are in short supply in the industry, and promote the introduction of talents, such as attractive salary, subsidies, stock options, and technology stocks, waiting for the way. Of course, we should also fully respect their development needs and create a comfortable working atmosphere. Farmers are the mainstay and promoter of returning home business, and must upgrade the human capital of returning entrepreneurial migrant workers and build a sound modern rural vocational education system. Make full use of the convenience of the Internet, cooperate with rural vocational schools, adult schools, community education centers and farmers' teaching points to form a combined cultivation model. Secondly, in order to improve the efficiency of training, in addition to pre-employment training for returning entrepreneurs, it is necessary to establish supervision and tracking service support system after entrepreneurship and entrepreneurship; "Creating the second generation" is the core of the upgrade and transformation of returning entrepreneurs. Characters should pay attention to the education of future generations of migrant workers, guide the establishment of lofty ideals, focus on knowledge management in business management, economics, and marketing, and introduce more advanced experiences for their hometowns to promote continuous innovation and innovation.

Breaking the industrial structure restrictions of migrant workers returning to their hometowns, the extension and expansion of the industrial chain is the key. Due to the strong advocacy and support of the government, the intensive development trend of China's returning entrepreneurship enterprises is obvious, but the industrial chain is short and the added value is low. Inspired by reverse service innovation such as $\mathrm{C} 2 \mathrm{~B}$, rural industry development can start from the reverse of the supply process of existing products or services, discover new user needs and create new value. For example, through the establishment of market-oriented agricultural productive service organizations, the construction of platform-based enterprises, or the transformation of agricultural production and processing enterprises to agricultural service enterprises, guiding or better radiation to drive the transformation of industrial development mode. In recent years, some places have provided physical trading places or virtual trading spaces through their processed products and agriculture-related services to commu- 
nicate the upstream and downstream industrial chains of agriculture and suppliers and consumers of agricultural products, and to play a role as a service intermediary and support.

\subsection{Rules: Formulate Persistent-Effect Development Plans and Create a Distinctive Corporate Culture}

China's returning home business under the new economic normal will inevitably face many opportunities and challenges. It cannot rely on the government and help the development. It must have the ability to stand on the existing soil conditions. Enterprises should cultivate the awareness and ability of strategic planning, build their own characteristics, and enhance cultural soft power to cope with the constant changes in the environment.

The strategic positioning of returning home entrepreneurs first pays attention to the limited nature of environmental resources, fully fits with the local characteristics, and makes full use of their own advantages. Second, we must take into account China's future industrial development and globalization trends. Therefore, we must pay attention to the establishment of innovative mechanisms and improve the development efficiency of existing resources when strategic positioning. At the same time, we must make good use of the propaganda advantages of the all-media era, based on quality, combine their own characteristics and advantages, shape the brand image, avoid the lack of personalization, and win the initiative in the increasingly competitive market.

\section{Conflicts of Interest}

The author declares no conflicts of interest regarding the publication of this paper.

\section{References}

[1] Fang, H.P. (2015) Promoting the Scientific Path of Returning Rural Migrant Workers to Start Their Own Businesses. Economic Daily.

[2] Zhang, F. (2011) Analysis of the Current Situation and Influencing Factors of Citizenization of the New Generation of Migrant Workers. Population Research, 6, 100-102.

[3] Zhang, G.Q. (2011) Migrant Workers Returning Home to Start Business: A Comparison of the Intergenerational Differences of Intention, Behavior and Effect. Statistics and Decision, 18, 94-95.

[4] Wang, G.M., Li, J.X. and Zheng, Q.Q. (2011) The Influence of Social Network Characteristics and Job Search Strategies on the Reemployment of the New Generation of Migrant Workers. Agricultural Economy, 10, 78-82.

[5] Zhao, Y.L. (2018) College Student Hometown Entrepreneurship in Fujian Province: A Structuration Theory-Based Study. Journal of Hebei University of Technology (Social Sciences Edition), 2, 79-80. 